\title{
Role of magnetic resonance imaging in prediction of outcome in traumatic diffuse axonal injury: A single- centre observational study
}

\author{
Suraj Thulung $M C h^{1}$ iD, Nikung Yogi $M C h^{2}$ iD \\ ${ }^{1}$ Upendra Devkota Memorial National Institute of Neurological and Allied Sciences, Bansbari, Kathmandu, Nepal \\ ${ }^{2}$ Manipal College of Medical Sciences, Pokhara, Nepal
}

Date of submission: $17^{\text {th }}$ July 2020

Date of acceptance: $2^{\text {nd }}$ May 2021

Date of publication: $1^{\text {st }}$ September 2021

\begin{abstract}
Introduction: Incidence of diffuse axonal injury has been estimated at $40-50 \%$ of hospitalizations. Recently, much interest has been directed towards the potential of newer imaging sequences of magnetic resonance imaging to investigate diffuse axonal injury (DAI) and to prognosticate the outcome. In this study, we correlated the magnetic resonance imaging grades of diffuse axonal injury with clinical outcome in terms of Glasgow Outcome Scale (GOS). Methods and Materials: A hospital based observational study was carried out at Upendra Devkota Memorial National Institute of Neurological and Allied Sciences, Kathmandu in 69 patients of diffuse axonal injury between November 2017 to November 2018. Data was collected on patient and trauma characteristics, as well as neurological assessment and MRI findings. Outcome was assessed as favourable and unfavourable GOS for various MRI grades of diffuse axonal injury.
\end{abstract}

Results: There were $21.74 \%, 42.03 \%$ and $36.23 \%$ of cases with grade I, II and III diffuse axonal injury respectively. There were $0(0 \%), 2(11.8 \%)$ and $15(88.2 \%)$ cases of MRI grade I, II and III diffuse axonal injury in favourable GOS group and $15(28.8 \%), 27(51.9 \%)$ and $10(19.2 \%)$ cases of MRI grade I, II and III diffuse axonal injury in unfavourable GOS group $(\mathrm{p}=0.00)$.

Conclusion: This study showed that there was a significantly higher chance of unfavourable outcome with increasing MRI grades of diffuse axonal injury.

Key words: Diffuse axonal injury, Glasgow outcome scale, Magnetic resonance imaging.

\section{Introduction}

$\mathrm{T}$ raumatic brain injury (TBI) is a major global health problem and is one of the most important causes of morbidity and mortality worldwide. Estimates by

Access this article online
Website: https://www.nepjol.info/index.php/NJN
DOI: https://doi.org/10.3126/njn.v18i3.39184
HOW TO CITE
Thulung S, Yogi N. Role of magnetic resonance imaging in
prediction of outcome in traumatic diffuse axonal injury: A single-
centre observational study. NJNS. 2021;18(3):39-43.

Address for correspondence:

Dr Suraj Thulung

Associate Professor, Department of Neurosurgery,

Upendra Devkota Memorial National Institute of Neurological and Allied Sciences,

Bansbari, Kathmandu, Nepal.

E-mail: surajthulung@yahoo.com

Phone: +9779841469630

Copyright (C) 2021 Nepalese Society of Neurosurgeons (NESON)

ISSN: 1813-1948 (Print), 1813-1956 (Online) the World Health Organization (WHO) indicate that 57 million people have been hospitalized with one or more TBIs globally. ${ }^{1}$ In the United States, recent statistics from the National Centre for Injury Prevention and Control (NCIPC) reveal that approximately 1.4 million cases of TBI were reported each year from 1995 through $2001 .{ }^{2}$ In the United Kingdom, more than 1 million patients attend hospital each year suffering from head injury. ${ }^{3}$

Mortimer et al studied 7 case-control studies and reported a relative risk of developing Alzheimer's disease of 1.82 for head injury with loss of consciousness. ${ }^{4}$ Its incidence has been estimated at $40-50 \%$ of TBI hospitalizations and rises to $100 \%$ in motor vehicle accidents where there was loss of consciousness. ${ }^{5}$ In the acute management of a TBI patient, computed tomography $(\mathrm{CT})$ is routinely the first imaging method since it can be performed rapidly to detect pathology that is critical for the early medical management of cerebral trauma. However, several studies have shown magnetic resonance imaging (MRI) to be superior to $\mathrm{CT}$ in the detection of intraparenchymal traumatic lesions, both in the acute and chronic stages, regardless of the severity of injury. Despite this, the clinical use of MRI in the imaging of TBI has not achieved a universally accepted role. MRI studies are often performed in subacute and 
chronic stages of recovery from TBI, with the intention of answering specific neuropsychiatric questions regarding the patient's status and/or to assist in evaluating outcome. The sensitivity in detecting TBI related anatomical abnormalities by MRI depends on the image sequence and methods used. Clinical MRI studies are still often performed with old or poorly equipped MRI systems and with ordinary visual evaluation. A seldom raised aspect is the role of early imaging in documenting intracranial injury, since conventional MRI is thought to underestimate the extent of diffuse axonal Injury (DAI). Recently, much interest has been directed towards the potential of newer imaging sequences of MRI like Fluid Attenuated Inversion Recovery (FLAIR), susceptibility weighted imaging (SWI), diffusion-weighted imaging (DWI) and diffusion tensor imaging (DTI) techniques to investigate DAI.There is growing interest in evaluating MRI as a prognostic tool with the advent of these improved newer generations imaging modalities.

In this study we evaluated the cases of DAI in terms of its MRI findings, grades of DAI according to the lesions seen in various MRI sequences and compared the outcome in terms of GOS in accordance with various radiological grades and the site of the lesion.

\section{Methods and Materials}

A prospective analytical study was done in patients of diffuse axonal injuries (DAI) admitted to Upendra Devkota Memorial National Institute of Neurological and Allied Sciences in between November 2017 to November 2018. Patients with DAI were graded according to the MRI findings and their outcome at 6 months was studied in terms of the Glasgow Outcome Scale (GOS). The working definition of DAI in our study was any patient with head injury having loss of consciousness (LOC) more than 6hours, post traumatic amnesia (PTA) and neurological status after resuscitation not explainable by CT findings. All patients with head injury presenting to the casualty were initially evaluated by a neurosurgical registrar on duty. All the patients were evaluated with an initial CT scan of the head and if the criteria of diffuse axonal injury were met according to the working definition, an MRI scan of the brain was performed once the patient was hemodynamically stable and cooperative enough for the procedure. This consisted of T1 and T2 weighted images along with FLAIR, DWI and SWI sequences. All the scans were interpreted and graded by the consultant radiologists along with a neurosurgical registrar and a consultant. Patients unsuitable for MRI scanning due to hemodynamic instability or those having metallic implants as well as those not consenting for the study and scanning were excluded from the study. Treatment of the patients was continued under the usual principles and institutional guidelines of head injury.
At 6 months of follow-up, recovery status was studied according to the GOS of the patient and charted in the structured pro forma. For ease of evaluation, GOS was dichotomised into good outcomes for good or moderate functional disability (GOS 1 and 2, respectively) or poor outcomes for those who were severely disabled, were vegetative, or died (GOS 3, 4, or 5, respectively). Data collection was completed after completion of 6 months follow-up period. All the categorical data were compared using Chi-square test or Fisher Exact Test wherever chisquare was inappropriate at $95 \% \mathrm{CI}$. GOS at discharge and 6 months were compared with the grades of DAI according to the MRI with appropriate statistical tools using SPSS 20 and p-value less than or equal to 0.05 were considered statistically significant. Ethical clearance from the Institutional Review Body was taken.

\section{Results}

There were 69 cases of DAI during the study period of which 52 (75.36\%) patients had favourable GOS and 17 $(24.64 \%)$ patients had unfavourable GOS. The Mean age of the patients enrolled in the study was $29.35 \pm 15.06$ years (1-63). There were $52(75.36 \%)$ male and $17(24.64 \%)$ females in this study. The mean duration to reach the hospital after injury was $1.753 \pm 0.62$ hours. RTA was the most common mode of injury, including 49 (71\%) patients followed by fall from height $(17,24.6 \%)$ and assault $(3$, $4.3 \%)$. The severity of head injury in terms of GCS shows higher incidences of Low GCS score in the unfavourable group and vice versa $(\mathrm{p}=0.00)$ (Table 1$)$.

In our series $16(23.19 \%)$ of patients had other systemic injuries as well. Long bone fractures $9(13.04 \%)$ were the commonest associate injuries whereas multiple system injuries were seen in $4(5.80 \%)$. There was no significant difference in the outcomes when associated systemic injuries were considered $(\mathrm{p}=0.942)$. Similarly, there were $43(62.32 \%)$ cases where there were other co-existing injuries in the brain like extradural hematomas, subdural hematomas, subarachnoid haemorrhages etc. and again there was no significant difference in the two groups when these factors were taken into considerations. In our series $59(85.581 \%)$ patients were managed conservatively and $10(14.49 \%)$ were operated for various head injury related consequences. Operations for other systemic injuries were not taken into consideration in our study. There were no significant differences in outcomes of operated and nonoperated groups $(\mathrm{p}=0.105)$.

On analysing the unfavourable and favourable GOS, there were $0(0 \%), 2(11.8 \%)$ and $15(88.2 \%)$ cases of grade 1, 2 and 3 DAI in unfavourable GOS group and 15 (28.8\%), 27(51.9\%) and $10(19.2 \%)$ cases of grade 1,2 and 3 DAI in favourable GOS group and the difference was statistically significant $(\mathrm{P}=0.00)$. This suggests that with higher MRI grades of DAI the chances of unfavourable outcomes increase significantly. 
MRI in traumatic brain injury

\begin{tabular}{|c|c|c|c|}
\hline Variables & $\begin{array}{c}\text { Unfavourable GOS (\%) } \\
\text { N=17 }(24.64 \%)\end{array}$ & $\begin{array}{c}\text { Favourable GOS (\%) } \\
\qquad \begin{array}{c}\mathrm{N}=52(75.36 \%)\end{array}\end{array}$ & P value \\
\hline \multicolumn{4}{|l|}{ Age (years) } \\
\hline $0-14$ & $2(11.8)$ & $11(21.2)$ & \multirow{3}{*}{0.56} \\
\hline $15-50$ & $12(70.6)$ & $36(69.2)$ & \\
\hline$>50$ & $3(17.6)$ & $5(9.6)$ & \\
\hline \multicolumn{3}{|l|}{ Sex } & \multirow{3}{*}{0.21} \\
\hline Male & $15(88.2)$ & 37 (71.2) & \\
\hline Female & $2(11.8)$ & $15(28.8)$ & \\
\hline \multicolumn{3}{|l|}{ Time since injury } & \multirow{4}{*}{0.21} \\
\hline$<6 \mathrm{Hrs}$ & $8(47.1)$ & $16(30.8)$ & \\
\hline 6-24 Hrs & $5(29.4)$ & $33(63.5)$ & \\
\hline$>24 \mathrm{Hrs}$ & $4(23.5)$ & $3(5.8)$ & \\
\hline \multicolumn{3}{|l|}{ Mode of injury } & \multirow{4}{*}{0.89} \\
\hline RTA & $13(76.5)$ & $36(69.2)$ & \\
\hline Fall & $4(23.5)$ & $13(25.0)$ & \\
\hline Assault & $0(0)$ & $3(5.8)$ & \\
\hline \multicolumn{3}{|l|}{ GCS } & \multirow{4}{*}{$0.00 *$} \\
\hline $13-15$ & $0(0)$ & $16(30.8)$ & \\
\hline $9-12$ & $2(11.8)$ & $29(55.8)$ & \\
\hline $3-8$ & $15(88.2)$ & $7(13.5)$ & \\
\hline
\end{tabular}

Table 1: Various parameters associated with DAI according to their outcomes.

\begin{tabular}{l|c|c|c}
\hline $\begin{array}{l}\text { Independent Variables } \\
\text { Other systemic injury }\end{array}$ & $\begin{array}{c}\text { Unfavourable } \\
\text { GOS (\%) }\end{array}$ & $\begin{array}{c}\text { Favourable } \\
\text { GOS (\%) }\end{array}$ & P value \\
$\begin{array}{l}\text { None } \\
\text { Long bone fracture }\end{array}$ & $13(76.5)$ & $40(76.9)$ & \\
Chest injury & $3(17.6)$ & $6(11.5)$ & 0.942 \\
Multiple systems & $0(0)$ & $3(5.8)$ & \\
Other traumatic lesions co-existing with DAI & $1(5.9)$ & $3(5.8)$ & \\
Yes & $9(52.9)$ & $34(65.4)$ & 0.397 \\
No & $8(47.1)$ & $18(34.6)$ & \\
Intervention & $12(70.6)$ & $47(90.4)$ & 0.105 \\
Conservative & $5(29.4)$ & $5(9.6)$ & \\
Operated & & \\
\hline
\end{tabular}

Table 2: Other associate injuries in our series and interventions.

\begin{tabular}{l|c|c|c|}
\hline DAI Grade & Unfavourable GOS & Favourable GOS & Pvalue \\
\hline Grade I & $0(0 \%)$ & $15(28.8 \%)$ & $0.000^{*}$ \\
\hline Grade II & $2(11.8 \%)$ & $27(51.9 \%)$ & \\
\hline Grade III & $15(88.2 \%)$ & $10(19.2 \%)$ & \\
\hline
\end{tabular}

Table 3: Relation between various DAI grades and outcome (GOS).

\section{Discussion}

The mean age of the patients enrolled in the study was 29.35 years ( 1 to 63 ) with a standard deviation of 15.066. There was a higher incidence of DAI noted in the adult population (15-50 years, $69.6 \%)$ than in the younger age group $(<14$ years, 18.8\%) and older age group $(>50$ years, $11.6 \%$ ). Most of the patients with DAI in this study were males $(75.36 \%)$. RTA was the most common mode of injury comprising 49 (71\%) patients followed by fall from height $(17,24.6 \%)$. Adams et al had found in their classical series that DAI was associated with RTA in $69 \%$ of cases and fall in $18 \%$ of cases. ${ }^{6}$

There were $23.19 \%$ cases of DAI with mild head injury, $44.93 \%$ cases with moderate head injury and $31.88 \%$ cases with severe head injury in our series. In a 
study of 20 consecutive cases of mild head injury, found $30 \%$ of cases had abnormalities compatible with DAI in white matter. ${ }^{7}$ Another study by Chelly et al reported $83.6 \%$ of case of DAI had severe head injury and $12.9 \%$ had moderate head injury. ${ }^{8}$

CT scan represents first line of investigation in any acute head injury as it is considered safer than MRI. ${ }^{9}$ It is also sensitive enough to detect any lesions that require immediate surgical intervention. ${ }^{9}$ Patient's outcome and CT scan finding has been found to have correlate well in few studies. ${ }^{9,10}$ It however lacks sensitivity to detect diffuse axonal injuries and predict its outcome. Zimmerman et al reported the first radiological study comparing CT and MRI in acute, sub-acute and chronic head injuries. ${ }^{10}$ Similarly Eisenberg $\mathrm{HM}$ et al found correlation of CT findings with patient's outcome. ${ }^{11}$ Zimmerman et al made the first observation that MRI was better in diagnosis of DAI that included small haemorrhagic lesions of corpus callosum, upper brainstem, cortico-medullary junction, parasagittal area and basal ganglia. ${ }^{10}$ Fisher et al found $60 \%$ of patients to have traumatic injuries in T1 and T2 sequence of MRI that been missed by $\mathrm{CT}$ scan when performed within 3 days. ${ }^{12}$ Gentry used neuro-pathological findings and grading of DAI described by Adams et al and transferred it arbitrarily to MRI, classifying it into three grades: Grade 1 DAI consisted of lesions in subcortical white matter mostly of frontal and parietal lobes; grade2 consisted of lesions in the corpus callosum and grade 3 consisted of those with lesions in the brainstem. ${ }^{6,13}$ In our series there were $21.74 \%, 42.03 \%$ and $36.23 \%$ of cases with grade 1, 2 and 3 DAI respectively. Adams et al in their autopsy findings had overwhelmingly high frequency of grade $3 \mathrm{DAI}$ and the percentage was in increasing trend to the grade of DAI. ${ }^{6}$ This can be explained on the basis of aforementioned literature that; the mortality rate is also in increasing trend with increasing severity of DAI similar to our results.

There were $0 \%, 11.8 \%$ and $88.2 \%$ cases of grade 1 , 2 and 3 DAI respectively in unfavourable GOS group and $28.8 \%, 51.9 \%$ and $19.2 \%$ cases of grade 1,2 and 3 DAI respectively in favourable GOS group $(\mathrm{P}=0.00)$. This suggests there is significantly higher chances of unfavourable outcomes with increasing DAI severity. Lasagares et al have also observed worsening outcome with increase in DAI grade in MRI whereas Skandsen et al have observed that only grade 3 DAI were associated with poor outcomes. ${ }^{15,16} \mathrm{Kampfl}$ et al on the other hand believed that both corpus callosum lesions and Brainstem lesions are both independent predictors of persistent vegetative state. ${ }^{17}$

\section{Conclusion}

Our study showed that there was a significantly higher chance of getting an unfavourable outcome with increasing MRI grades of DAI.

\section{Conflict of Interest: None Source(s) of support: None}

\section{References}

1. Murray CJ, Lopez AD. Global burden of disease and injury series, vol. II. Cambridge, MA: Harvard School of Public Health on behalf of the World Health Organization and the World Bank, 1996. PMID: 21250374

2. William SP, David ES, Lisa CM, Victor GC. Emergency department visits for traumatic brain injury in older adults in the United States. West J Emerg Med. 2012;13: 289-93. https://doi. org/10.5811/westjem.2012.3.11559

3. Kay A, Teasdale G. Head injury in the United Kingdom. World J Surg. 2001;25:1210-20. https:// doi.org/10.1007/s00268-001-0084-6

4. Mortimer JA, French LR, Hutton JT, Schuman LM. Head injury as a risk factor for Alzheimer's disease. Neurology. 1985;35:264-7. https://doi.org/10.1212/ wnl.35.2.264

5. Meythaler JM, Peduzzi JD, Eleftheriou E, Novack TA. Current concepts: Diffuse axonal injuryassociated traumatic brain injury. Arch Phys Med Rehabil. 2001;82:1461-71. https://doi.org/10.1053/ apmr.2001.25137

6. Adams JH, Doyle D, Ford I, Gennarelli TA, Graham DI, McLellan DR. Diffuse axonal injury in head injury: Definition, diagnosis and grading. Histopathology. 1989;15:49-59. https://doi. org/10.1111/j.1365-2559.1989.tb03040.x

7. Mittl RL Jr, Grossman RI Jr, Hiehle JF, Hurst RW Jr, Kauder DR, Gennarelli TA, et al. Prevalence of MR evidence of diffuse axonal injury in patients with mild head injury and normal head CT findings. Am J Neuroradiol. 1994;15:1583-89. PMID: 7985582

8. Chelly H, Chaari A, Daoud E, Dammak H, Medhioub F, Mnif J, et al. Diffuse axonal injury in patients with head injuries: An epidemiologic and prognosis study of 124 cases. J Trauma. 2011;71:838-46. https://doi. org/10.1097/TA.0b013e3182127baa

9. Zimmerman RA, Bilaniuk LT, Hackney DB, Goldberg HI, Grossman RI. Head injury: early results of comparing $\mathrm{CT}$ and high-field $\mathrm{MR}$. Am Roentgenol. 1986;147:1215-22. https://doi. org/10.2214/ajr.147.6.1215

10. Eisenberg HM, Gary HE Jr, Aldrich EF, Saydjari C, Turner B, Foulkes MA, et al. Initial CT findings in 753 patients with severe head injury. A report from the NIH Traumatic Coma Data Bank. J 
Neurosurg. 1990;73:688-98. https://doi.org/10.3171/ jns.1990.73.5.0688

11. Zimmerman RA, Bilaniuk LT, Gennarelli TA. Computed tomography of shearing injuries of the cerebral white matter. Radiology. 1978;127:393-6. https://doi.org/10.1148/127.2.393

12. Fiser SM, Johnson SB, Fortune JB. Resource utilization in traumatic brain injury: The role of magnetic resonance imaging. Am Surg. 1998;64:1088-93. PMID: 9798776

13. Gentry LR. Imaging of closed head injury. Radiology. 1994;191:1-17. https://doi.org/10.1148/ radiology.191.1.8134551

14. Lagares A, Ramos A, Pérez-Nuñez A, Ballenilla F, Alday R, Gómez PA, et al. The role of MR imaging in assessing prognosis after severe and moderate head injury. Acta Neurochir. 2009;151:341-5. https://doi. org/10.1007/s00701-009-0194-8

15. Skandsen T, Kvistad KA, Solheim O, Strand IH, Folvik M, Vik A. Prevalence and impact of diffuse axonal injury in patients with moderate and severe head injury: A cohort study of early magnetic resonance imaging findings and 1-year outcome. J Neurosurg. 2010;113:556-63. https://doi. org/10.3171/2009.9.JNS09626

16. Kampfl A, Schmutzhard E, Franz G, Pfausler $\mathrm{B}$, Haring HP, Ulmer $\mathrm{H}$, et al. Prediction of recovery from post-traumatic vegetative state with cerebral magnetic resonance imaging. The Lancet. 1998;351:1763-7. https://doi.org/10.1016/S01406736(97)10301-4 